\title{
Research on new energy development comprehensive assessment model and application in China
}

\author{
Jing $\mathrm{Hu}^{1, *}$, Bibin Huang ${ }^{1}$, Dan $\mathrm{Du}^{2}$ and Dan Wang ${ }^{2}$ \\ ${ }^{1}$ State Grid Energy Research Institute Co., LTD, 102209, Beijing, China \\ ${ }^{2}$ North China Electric power university, 102206, Beijing, China
}

\begin{abstract}
In order to achieve the target of that non-fossil energy accounted for $15 \%$ in 2020 and $20 \%$ in 2030, new energy has developed rapidly in recent years in our country. However, the rapid development of new energy has brought many problems, such as the wind power curtailment, photovoltaic power curtailment, the unbalanced development in different regions and the imperfect policy. Therefore, it is necessary to make a comprehensive evaluation of the development of new energy, as the basis for the policy formulation and planning of new energy. In this paper, according to the characteristics of the new energy development in China, a comprehensive assessment model of new energy development is constructed, a set of assessment index system is proposed, which of the quantitative and qualitative combination, including energy production, energy consumption and policy mechanism from, and combining the Analytic Hierarchy Process(AHP) method to determine the weight coefficient. Finally, new energy development in Jiangsu province is taken as an example, the comprehensive evaluation of new energy development situation in 2018 is given.
\end{abstract}

\section{Foreword}

Under the dual pressure of global energy supply shortage and deterioration of ecological environment, the new energy development has become an important approach of many countries to promote energy transitions and respond to climate change. China is of the countries with the fastest development of new energy.

The present rapid growth of new energy incurs a lot of problems, e.g. the commonly-seen wind and photovoltaic power abandonment wind power curtailment and photovoltaic power curtailment in the western China with congregated wind and solar power projects, uncoordinated renewable resources and power among provinces and regions, unmatched power source construction and grid planning and construction, unsuitable policy incentive mechanism, etc. The development of new energy requires not only clear objectives and effective policy support, but also the comprehensive assessment in line with the national situation and basic conditions of developing new energy. The multi-dimensional comprehensive assessment with distinct advantages and disadvantages and reasonable sequence can serve as the basis for the government to set the new energy development goals and implement differentiated supporting policies, and provide explicit market orientation to the enterprises[1].

Some scholars have conducted researches on the assessment of new energy or renewable energy in China, which mainly include the assessment of renewable energy resources[2], assessment of new energy power generation projects[3-4], assessment of new energy industry development capability[5-8], assessment of coordinated development of new energy and grid[9-10].

Based upon the new energy statistics system, the paper establishes the comprehensive assessment model of new energy development in China, sets up the new energy development assessment index system, and in line with the resource endowment and present status of new energy of Jiangsu Province evaluates and analyzes the overall development of new energy of this province in 2018, which offers the reference of policy making, new energy and grid planning and industry development.

\section{New energy development comprehensive assessment model}

Figure 1 shows the flow block of comprehensive assessment model of new energy development that mainly includes the four aspects of establishment of assessment index system, assessment of single index, determination of index weight coefficient and comprehensive assessment of new energy development.

\subsection{Establishment of assessment index system of new energy development}

The present status (or development) assessment of new energy development can be represented by a vector $\mathrm{X}$ where each weight shows the new energy development level from one perspective, so $\mathrm{X}$ is called the status

\footnotetext{
* Corresponding author: hujing901@qq.com
} 
vector of assessment that contributes to the index system of comprehensive assessment of target. Each assessment index describes the measured dimension of certain feature of the assessment target from a perspective.

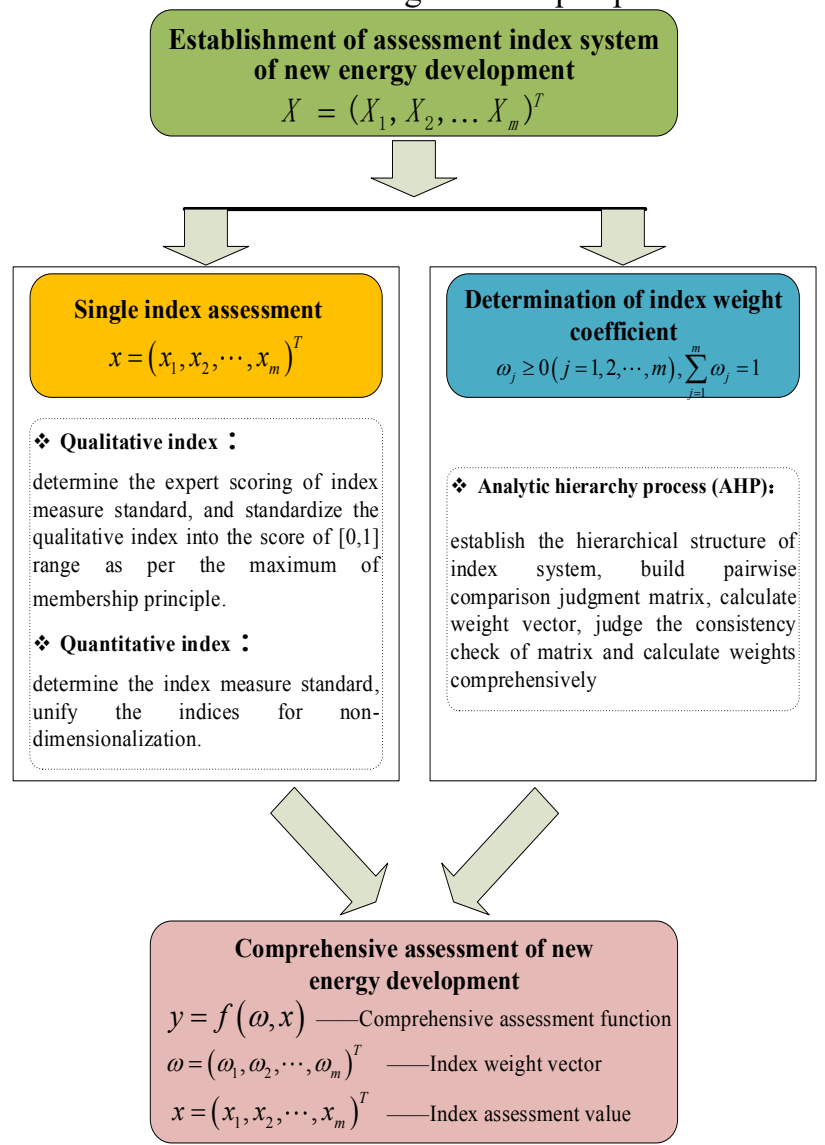

Fig. 1. Flow Block of the Comprehensive Assessment Model of New Energy Development.

\subsection{Single index assessment method}

\subsubsection{Qualitative index measure standard and assessment method}

The qualitative index refers to the assessment by expert scoring on the basis of preset index measure standard. A centesimal system is applied in the qualitative index assessment that the expert considers the actual conditions of an enterprise, follows the assessment elements and standards to assess each index, and standardize the qualitative index into the score of $[0,1]$ range as per the maximum of membership principle.

\subsubsection{Quantitative index measure standard and assessment method}

For the assessment of quantitative index, the indices should be pretreated such as non-dimensionalization and unification to determine the index measure standard. The pretreatment mainly includes the unification a nondimensionalization of index types. Generally speaking $x_{1}, x_{2}, \cdots, x_{m}$ may probably include "extremely big" index, "extremely small" index, "moderate index" and "range" index. If all the extremely big" index, "extremely small" index, "moderate index" and "range" index are involved in $x_{1}, x_{2}, \cdots, x_{m}$, the types of assessment index should be unified before the comprehensive assessment of candidate schemes.

In addition, incommensurability exists among $x_{1}, x_{2}, \cdots, x_{m}$ due to their respective unit and different magnitude, which causes inconvenience of comparative and comprehensive assessment of index y. Therefore, to eliminate the influence of different units of indices and the great disparity of numerical magnitude, the assessment indices should be subject to nondimensionalization, which is also known as the standardization or normalization of index data. It eliminates the influence of original index unit by mathematical conversion. The commonly applied methods include "standardization", "extremum" and "efficacy coefficient".

\subsection{Determination of index weight coefficients}

For the purpose of assessment, the relative importance of assessment indices is different. Such extent of relative importance can be described by weight coefficient. If $\omega_{j}$ is the weight coefficient of assessment index $x_{j}$.

$$
\omega_{j} \geq 0(j=1,2, \cdots, m), \sum_{j=1}^{m} \omega_{j}=1
$$

The commonly applied methods to determine the index weight include AHP, expert scoring, etc. When the assessed target and assessment index (value) are predetermined, whether the weight coefficients are reasonably determined is related with the reliability of comprehensive assessment result. Therefore, the determination of weight coefficient should be treated with special cautiousness.

\subsection{Comprehensive assessment of new energy development}

Build the comprehensive assessment function of $y=f(\omega, x)$ and calculate the comprehensive assessment result, where $\omega=\left(\omega_{1}, \omega_{2}, \cdots, \omega_{m}\right)^{T}$ is the index weight vector and $x=\left(x_{1}, x_{2}, \cdots, x_{m}\right)^{T}$ is the status vector of respective assessment index, i.e. the assessment value of index.

\section{Assessment index system}

In accordance with the production, consumption, mechanism and science and technology aspects of the "energy production and consumption revolution", given the regional new energy development characteristics in China, the key factors of measurement of new energy 
development level are selected on the basis of existing new energy development statistical index system. By qualitative-quantitative combination, the new energy development comprehensive assessment index system is established for the three aspects namely new energy production, consumption and policy mechanism, which contains three layers, three dimensions and twelve key indices(as shown in Table 1).

Table 1. Comprehensive Assessment Index System of New Energy Development.

\begin{tabular}{|c|c|c|}
\hline $\begin{array}{l}\text { Layer of } \\
\text { objective }\end{array}$ & $\begin{array}{l}\text { Layer of } \\
\text { criteria }\end{array}$ & Layer of index \\
\hline \multirow{12}{*}{$\begin{array}{l}\text { Comprehensive } \\
\text { assessment of } \\
\text { new energy } \\
\text { development }\end{array}$} & \multirow{4}{*}{$\begin{array}{l}\text { Energy } \\
\text { production }\end{array}$} & $\begin{array}{c}\text { Share of new energy installed } \\
\text { capacity }\end{array}$ \\
\hline & & $\begin{array}{l}\text { Share of incremental installed } \\
\text { capacity of new energy }\end{array}$ \\
\hline & & $\begin{array}{c}\text { New energy installed } \\
\text { capacity per capita }\end{array}$ \\
\hline & & $\begin{array}{l}\text { New energy installed } \\
\text { capacity per unit GDP }\end{array}$ \\
\hline & \multirow{4}{*}{$\begin{array}{c}\text { Energy } \\
\text { consumption }\end{array}$} & $\begin{array}{l}\text { Share of new energy power } \\
\text { in total power consumption }\end{array}$ \\
\hline & & $\begin{array}{l}\text { New energy power output per } \\
\text { capita }\end{array}$ \\
\hline & & $\begin{array}{c}\text { New energy power output per } \\
\text { unit GDP }\end{array}$ \\
\hline & & $\begin{array}{c}\text { Ratio of wind power } \\
\text { curtailment and photovoltaic } \\
\text { power curtailment }\end{array}$ \\
\hline & \multirow{4}{*}{$\begin{array}{c}\text { Policy } \\
\text { mechanism }\end{array}$} & Industry development \\
\hline & & Incentive policy \\
\hline & & Development planning \\
\hline & & Administrative rules \\
\hline
\end{tabular}

\subsection{Energy production}

The comprehensive assessment indices of production include four indices of share of new energy installed capacity, share of incremental installed capacity of new energy, new energy installed capacity per capita and new energy installed capacity per unit GDP. The share of new energy installed capacity refers to the share of new energy installed capacity in the total installed capacity of electric power that directly reflects the present position of new energy development in the whole power supply system; the share of incremental installed capacity of new energy refers to the annual incremental installed capacity of new energy in the annual incremental installed capacity of electric power that directly presents the growth rate proportion of new energy development and future orientation in the whole power supply system, facilitating the judgment of future trend; the new energy installed capacity per capita refers to the cumulative new energy installed capacity per capita that to some extent shows the density of new energy development; the new energy installed capacity per unit GDP refers to the cumulative new energy installed capacity of unit GDP that to some extent illustrates the relation between new energy development and gross production, which is the green development of social economy.

\subsection{Energy consumption}

The comprehensive assessment indices of energy consumption include four indices of share of new energy power in total power consumption, new energy power output per capita, new energy power output per unit GDP and ratio of wind power curtailment and photovoltaic power curtailment. The share of new energy power in total power consumption refers to the ratio between annual power output of new energy and annual power consumption of the whole society that directly reflects the current contribution of new energy power to the power consumption; the new energy power output per capita refers to the all-year cumulative new energy power output per capita that to some extent shows the density of new energy power output; the new energy power output per unit GDP refers to the cumulative new energy power output of unit GDP that to some extent illustrates the relation between new energy power output and gross production, which is the green development of social economy; the ratio of wind power curtailment and photovoltaic power curtailment refers to the share of forced reduction of new energy power output in actual operation in the total all-year output that to some extents reflects the level of effective utilization of new energy power output.

\subsection{Policy mechanism}

The comprehensive assessment indices of policy mechanism also include four indices of industry development, incentive policy, development planning and administrative rules. The index of industry development represents the development scale, quality and exterior policy environment of new energy industry. Since the installed capacity of new energy of provinces may not be directly related with the provincial industry development, the development of new energy industry is preferably to be measured and assessed on the national level. Therefore, the consideration of provincial industry development focuses on the reference to some extent and assessment of industry policies. The index of incentive policy is to show the appropriateness of developing the incentive policies like financial subsidy as well as the effectiveness of implementation, which reflect the perfectness of new energy development policies; the index of development planning mainly measures the completion and science of new energy development planning; the index of administrative rules shows the perfectness of relevant administrative documents and regulations on new energy, including the formulation and implementation of administrative rules. The former mainly covers the perfectness, timeliness, pertinence and revision in appropriate time of policy making while the latter mainly covers the practicability and implementation result of standards and rules.

\section{Determination of index assessment measures}




\subsection{Method of determining the qualitative index measure standards}

For the qualitative index assessment of the comprehensive assessment index system of new energy development, the industry experts will consider the actual conditions of an enterprise and assessment elements, and use five-level measure standards to assess each index(as shown in Table 2).

Table 2. Measure Standard of Qualitative Index of New Energy Comprehensive Assessment.

\begin{tabular}{c|c|c|c|c}
\hline Excellent & Good & Moderate & Bad & Worse \\
\hline$[0.8,1.0]$ & {$[0.7,0.8)$} & {$[0.6,0.7)$} & {$[0.5,0.6)$} & {$[0,0.5)$} \\
\hline
\end{tabular}

\subsection{Method of determining the quantitative index measure standards}

Sample selection: owing to the different basic conditions, application environment, industry demand, etc. of new energy development, the new energy development scales of different provinces vary a lot together with apparently variant technical characteristics. Therefore, it is hard to select one or several provinces as the examples. In sampling, the whole country should be treated as a general example.

Measure standards: in the specific assessment of quantitative indices, the method of average is adopted to determine the measure standard value of each index, i.e. calculation of the relevant indices nationally. Such standards are more accurate and referential. The threeyear indices of 2016-2018 are calculated and the mean value or development trend is taken as the standard to determine the upper limit and lower limit of index, thus providing more accurate reference to the new energy development assessment of a certain province.

\section{Determination of index weights}

Determination of index weights is a critical step of comprehensive assessment of new energy development that decides the accuracy of assessment result. The AHP and expert comments are adopted to calculate the weights of the first layer assessment indices - energy production, energy consumption and policy mechanism, get the expert's pairwise comparison judgment matrix of index importance, calculate the index weights by AHP, and make reference to the expert comments in the system to optimize and adjust the index weight value so as to finalize the weights.

\subsection{Establish an index system of hierarchical structure}

The assessment indices are classified by membership relation as the objective layer, criteria layer and index layer to form the dominance relation from top to bottom, i.e. hierarchical structure.

\subsection{Build a judgment matrix of pairwise comparison}

After establishment of comprehensive index system of hierarchical structure, for the index factor of the upper layer, select the relevant sub-index in the lower layer for pairwise comparison of importance and build the judgment matrix.

\subsection{Calculate comprehensive weight}

Calculate the vector $\mathrm{W}$ of index and sequence the order of index importance. The weight value yielded by the judgment matrix is the separate weight value of index corresponding to its factor on the immediate upper layer. Therefore, these separate weight values need to be combined into the comprehensive weight value of index corresponding to the top layer. After the unification, $\sum_{j} y_{j}=1$ can be satisfied(as shown in Table 3 ).

For the setting of second-layer index weight, as there are too many indices, the AHP-based judgment matrix calculation may incur some problem of effectiveness and thus the calculation result of AHP method is corrected by expert comment.

Table 3. Comprehensive Assessment Index Weight of New Energy Development.

\begin{tabular}{|c|c|c|}
\hline $\begin{array}{l}\text { 1st layer index } \\
\text { and weight }\end{array}$ & 2nd layer index & $\begin{array}{c}\text { 2nd layer } \\
\text { weight }\end{array}$ \\
\hline \multirow{4}{*}{$\begin{array}{l}\text { Energy } \\
\text { production } \\
(0.54)\end{array}$} & $\begin{array}{c}\text { Share of new energy } \\
\text { installed capacity }\end{array}$ & 0.20 \\
\hline & $\begin{array}{c}\text { Share of incremental } \\
\text { installed capacity of new } \\
\text { energy }\end{array}$ & 0.40 \\
\hline & $\begin{array}{l}\text { New energy installed } \\
\text { capacity per capita }\end{array}$ & 0.20 \\
\hline & $\begin{array}{l}\text { New energy installed } \\
\text { capacity per unit GDP }\end{array}$ & 0.20 \\
\hline \multirow{4}{*}{$\begin{array}{c}\text { Energy } \\
\text { consumption } \\
(0.16)\end{array}$} & $\begin{array}{c}\text { Share of new energy } \\
\text { power in total power } \\
\text { consumption }\end{array}$ & 0.42 \\
\hline & $\begin{array}{c}\text { New energy power } \\
\text { output per capita }\end{array}$ & 0.23 \\
\hline & $\begin{array}{l}\text { New energy power } \\
\text { output per unit GDP }\end{array}$ & 0.12 \\
\hline & $\begin{array}{l}\text { Ratio of wind power } \\
\text { curtailment and } \\
\text { photovoltaic power } \\
\text { curtailment }\end{array}$ & 0.23 \\
\hline \multirow{4}{*}{$\begin{array}{c}\text { Policy } \\
\text { mechanism } \\
(0.3)\end{array}$} & Industry development & 0.14 \\
\hline & Incentive policy & 0.29 \\
\hline & Development planning & 0.29 \\
\hline & Administrative rules & 0.29 \\
\hline
\end{tabular}

\section{Case study of application in Jiangsu Province}

On the basis the new energy development data of Jiangsu Province in 2018, the comprehensive assessment of overall development level of new energy in Jiangsu 
Province has been conducted and the assessment results are shown in Table 4.

\subsection{Analytic assessment of energy production}

In recent years the installed capacity of new energy in Jiangsu Province experienced rapid growth. At the end of 2018 the new energy installed capacity of Jiangsu Province reached $23,679 \mathrm{MW}$ and the share of total installed capacity of new energy was $12.1 \%$; in 2018 the newly-added installed capacity of new energy reported $6,601 \mathrm{MW}$ that accounted for $46.2 \%$ of total incremental installed capacity.

Table 4. Comprehensive Assessment Results of New Energy Development in Jiangsu Province.

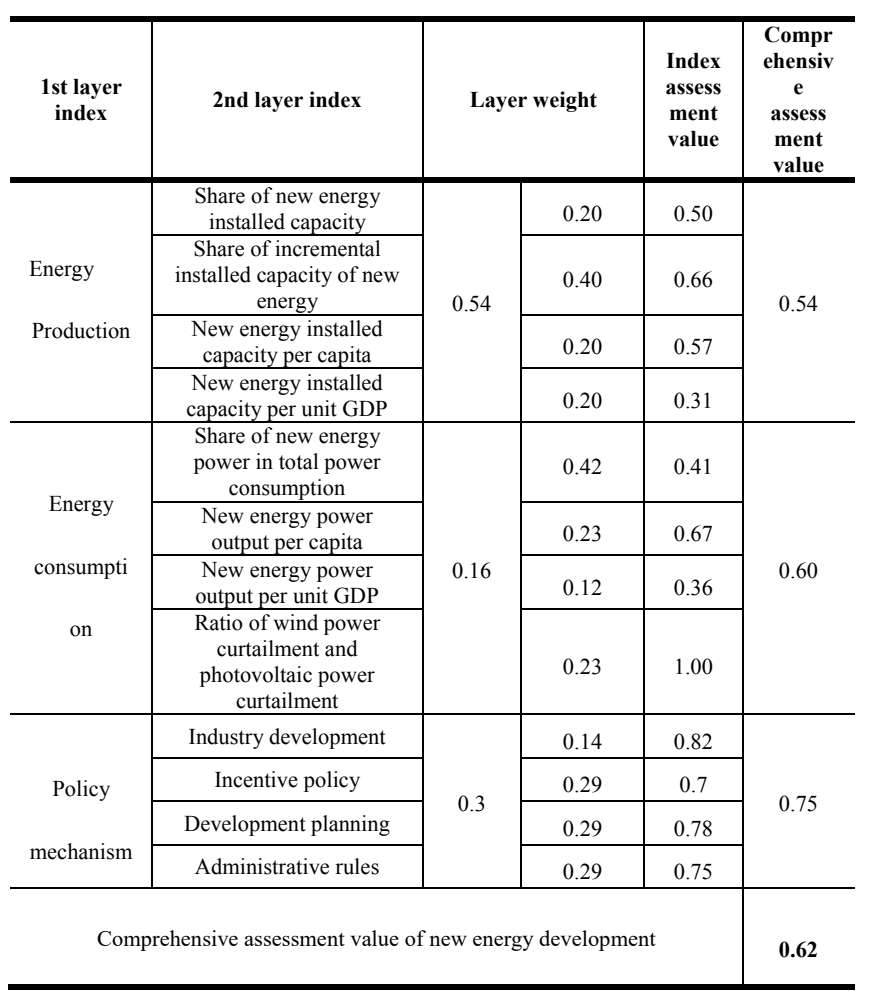

The assessment result of energy production aspect of new energy development in Jiangsu Province shows the high assessment value of share of incremental installed capacity, which should be attributed to the fast development of offshore wind power and distributed photovoltaic power in the past two years; the lower scores of share of new energy installed capacity and installed capacity per capita are due to the large basis of installed capacity and population scale of this province. The reason of low value of installed capacity per unit GDP is the booming industry of Jiangsu Province whose GDP ranks the No.2 in China. In future, Jiangsu is to continue accelerating the development pace of new energy. Figure 2 is the radar chart of new energy production assessment in Jiangsu province.
Share of new energy installed

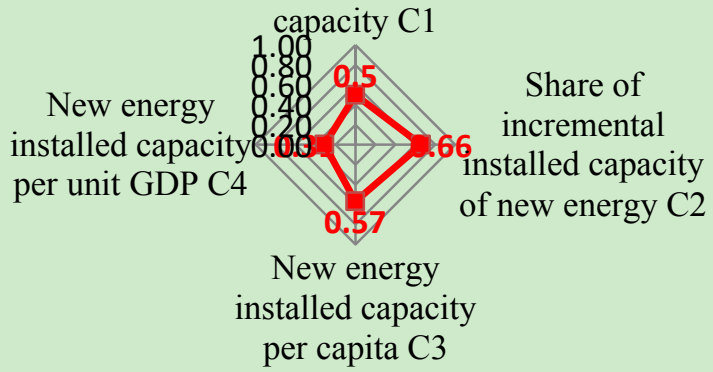
capacity $\mathrm{C} 1$

New energy

installed capacity

per capita $\mathrm{C} 3$

Fig. 2. Radar Chart of New Energy Production Assessment in Jiangsu Province.

\subsection{Analytic assessment of energy consumption}

In recent years, the new energy power output of Jiangsu Province kept rapid increase, annual new energy output reached $38.765 \mathrm{TWh}$ in 2018 which shared $4.1 \%$ of energy consumption. In 2018 there was no wind power curtailment and photovoltaic power curtailment in this province and thus the ratio of wind power curtailment and photovoltaic power curtailment was zero.

In accordance with the assessment result, the assessment value of ratio of wind power curtailment and photovoltaic power curtailment was zero is high since no wind power curtailment and photovoltaic power curtailment case occurred in this province; owing to the high levels of GDP per capita and total social power consumption in Jiangsu, there remains big space of improvement of new energy power share corresponding to the unit GDP and power consumption. Figure 3 is the radar chart of new energy consumption assessment in Jiangsu Province.

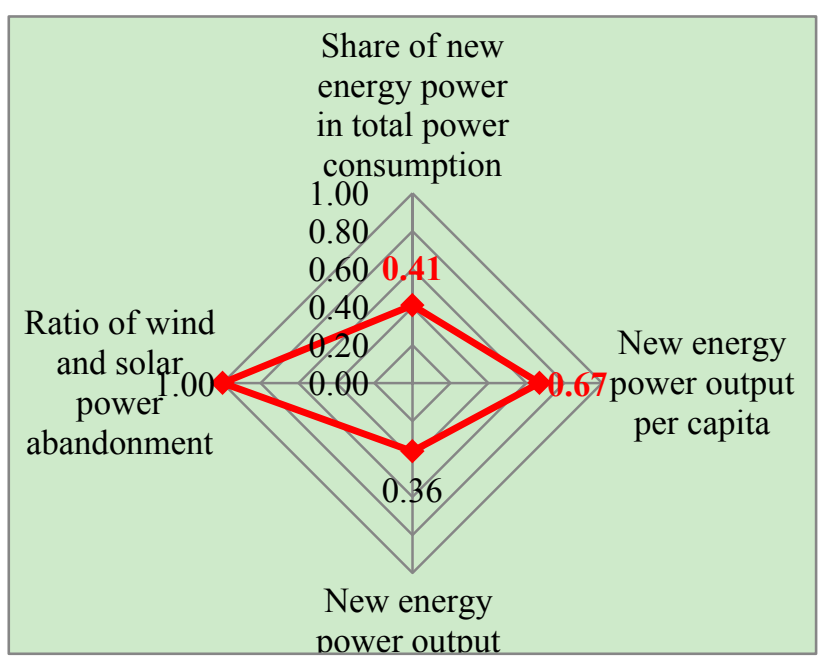

Fig. 3. Radar Chart of New Energy Consumption Assessment in Jiangsu Province.

\subsection{Analytic assessment of policy mechanism}

The assessment result of new energy policy mechanism of Jiangsu Province shows that the industry development 
is satisfactory, which benefits from its dominance in PV industry. But it should be noted the wind power sector is not as good as solar power. For the development planning and administrative rules, the province mainly uses the national requirements instead of enacting the effective administrative rules in line with its own conditions, and the provincial development planning is also not well coordinated and rigid. Figure 4 is the radar chart of new energy policy mechanism assessment in Jiangsu Province.

\subsection{Comprehensive assessment}

The assessment result of new energy development in Jiangsu Province shows the even distribution of all aspects of new energy development(as shown in Figure 5). The policy aspect gets the highest value because of the serial policy and administration documents issued by the national and provincial governments as well as the leading industry development of Jiangsu. In the aspect of energy production, the value is relatively lower due to the large overall power capacity and high GDP per capita. The energy consumption has big space of development due to the large overall consumption and more inbound power transmitted from other regions. Jiangsu Province should take advantage of its own industry strength and issue local supportive and administrative policies to further promote the new energy development, adjust the energy development structure and uplift the proportion of clean energy.

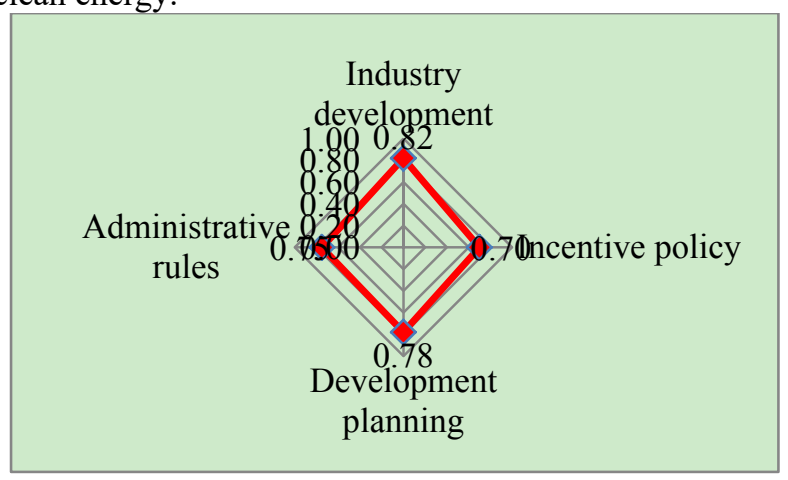

Fig. 4. Radar Chart of New Energy Policy Mechanism Assessment in Jiangsu Province.

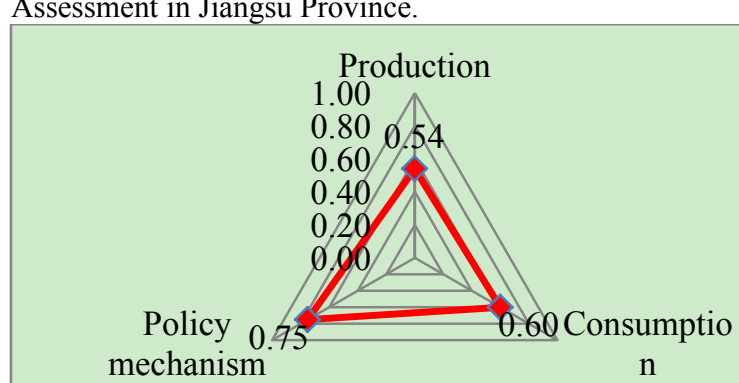

Fig. 5. Radar Chart of New Energy Development Comprehensive Assessment in Jiangsu Province.

\section{Conclusions}

Based on China's new energy development characteristics and present energy statistics, the paper proposes a set of new energy development comprehensive assessment model and index system, designs the detailed indices covering energy production, energy consumption and policy mechanism, and makes use of this model to analyze and assess the new energy development situation of Jiangsu Province in 2018, which demonstrates the feasibility and effectiveness of this model and index system. Through analytical assessment, the paper points out the existing strength of new energy development of Jiangsu Province as well as the problems that need special attention. This comprehensive assessment model can effectively assess the new energy development level of China and serve as the reference to the new energy policy making, new energy and grid planning, etc. of China.

This work is supported by Science and Technology Project of State Grid Corporation of China "Research on Analysis Techniques for Coordinated Development of New Energy, Distributed Generation, Energy Storage and Power Grid to Meet Global Energy Interconnection Demand".

\section{References}

1. LI Hong, DONG Liang, DUAN Hongxia. On Comprehensive Evaluation and Optimization of Renewable Energy Development in China [J]. Resources Science, 2011, 33(3): 431-440.

2. LI Jingjing, REN Dongming, ZHUANG Xing. Systemic evaluation method of renewable energy resources and its practical application [J]. Journal of Natural Resources, 2001, 16(4): 373-380.

3. ZHANG Ling, FANG Jianxin, ZHOU Peng. New Energy Power Generation Performance Evaluation Research were Reviewed-—Based on Multi-index Evaluation Method[J]. Technoeconomics \& Management Research, 2014, 1: 3-8.

4. HU Diangang, ZHANG Xuejiao, CHEN Naishi, et al. Taking a Research on multi-dimensional post evaluation methodology of new energy power generation projects[J]. Power System Protection and Control, 2015, 43(4): 10-17.

5. MENG Hao, CHEN Yingjian. Comprehensive Assessment on Developing Capability of New Energy Industry[J]. Forum on Science and Technology in China, 2010, 6: 51-58.

6. LIU Yezhi. On Building Green Evaluation System and Model of Benefits for Developing New Energy[J]. JOURNAL OF TAIYUAN NORMAL UNIVERSITY (Natural Science Edition), 2009, 8(3): 69-72.

7. LIU Zhen, ZHANG Xiliang, GAO Hu. Study on Design and Evaluation of the Development Scenarios of Renewable Energy[J]. CHINA POPULATION, RESOURCES AND ENVIRONMENT, 2011, 21(7): 28-32.

8. WANG Bo. Research on China's Urban New Energy Development Evaluation Index and its Application [D]. Tsinghua University, 2013: 18-24. 
9. DAI Hongcai, LI Qionghui, WANG Xiaolu. Research on the Evaluation Index System for Coordinated Development of New Energy and Smart Grid[J]. Energy Technology and Economics, 2011, 23(5): 18-23.
10. LU Zongxiang, LI Haibo, QIAO Ying. Flexibility Evaluation and Supply/Demand Balance Principle of Power System With High-penetration Renewable Electricity[J]. Proceedings of the CSEE, 2017, 37(1): 9-19. 